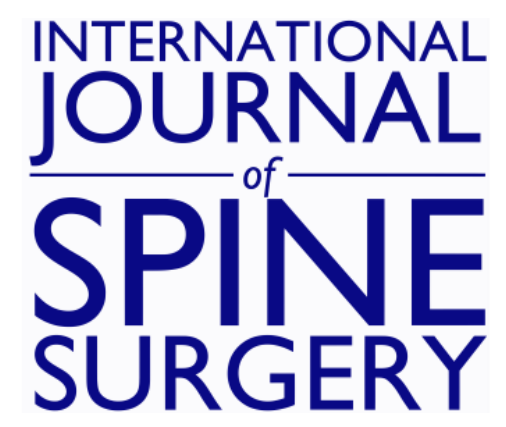

\title{
The Effects of Topical Vancomycin on Mesenchymal Stem Cells: More May Not Be Better
}

Stacey Chu, Nita Chen, Alexis B.C. Dang, Alfred C. Kuo and Alan B. C. Dang

Int J Spine Surg 2017, 11 (2)

doi: https://doi.org/10.14444/4012

http://ijssurgery.com/content/11/2/12

This information is current as of April 26, 2023.

Email Alerts Receive free email-alerts when new articles cite this article. Sign up at:

http://ijssurgery.com/alerts

The International Journal of Shing Surgerih 2397 Waterbury Circle, Suite 1,

Aurora, IL 60504, Phone: +1-630-375-1432

(C) 2017 ISASS. All Rights Reserved. 


\section{The Effects of Topical Vancomycin on Mesenchymal Stem Cells: More May Not Be Better}

Stacey Chu, BA, ${ }^{1}$ Nita Chen, BA, ${ }^{2}$ Alexis B.C. Dang, MD, ${ }^{3}$ Alfred C. Kuo, MD, PhD, ${ }^{3}$ Alan B. C. Dang, MD, 3

${ }_{1}^{1}$ Geisel School of Medicine at Dartmouth College, West Lebanon, NH, ${ }^{2}$ Albany Medical College, School of Medicine, Albany NY, ${ }^{3}$ University of California, San Francisco, Department of Orthopaedic Surgery, San Francisco, CA

\section{Abstract}

\section{Background}

The use of topical vancomycin is increasingly popular in spine surgery. Large retrospective reviews suggest that topical vancomycin provides a cost-effective decrease in post-operative infection. Currently, there is little that is known about the maximum dose that can be applied locally. When 1 gram of vancomycin is mixed into the bone graft and another 1 gram applied freely in a spine wound, the local concentration of antibiotic ranges from $260-2900 \mu \mathrm{g} / \mathrm{mL}$ in the immediate post-op period and $50-730 \mu \mathrm{g} / \mathrm{mL}$ by the second post-operative day. We hypothesized that exuberant doses of vancomycin would be toxic to mesenchymal stem cells (MSCs).

\section{Methods}

Bone marrow was obtained from the femoral canal of patients undergoing routine elective total hip arthroplasty. Mesenchymal stem cells were isolated using plastic adhesion. Cells were exposed to a wide range of doses of vancomycin for 24 hours and then assessed for viability. Osteogenic potential was assessed with alizarin red staining.

\section{Results}

There was dose-dependent cell death with vancomycin use. MSC death was $9.43 \%$ at $400 \mu \mathrm{g} / \mathrm{mL}(\mathrm{p}=0.047)$, $13.79 \%$ at $1600 \mu \mathrm{g} / \mathrm{mL}(\mathrm{p}=0.0047), 19.35 \%$ at $3200 \mu \mathrm{g} / \mathrm{mL}(\mathrm{p}<0.0001), 24.82 \%$ at $6400 \mu \mathrm{g} / \mathrm{mL}(\mathrm{p}<0.0001)$ and $51.83 \%$ at $12800 \mu \mathrm{g} / \mathrm{mL}$ of vancomycin $(\mathrm{p}<0.0001)$ in comparison to the control group containing no vancomycin.

\section{Conclusions}

Our in vitro study suggests that vancomycin has toxic effects on hMSCs, a cell population particularly important for bone formation. In the absence of any clinical evidence suggesting that "more vancomycin is better," and our data suggesting that more vancomycin is harmful in vitro, surgeons electing to use topical vancomycin in spine surgery should restrict their use to the doses currently reported in the available published studies unless specific reasons exist otherwise. This study does not establish a contraindication to the use of topical vancomycin, nor does it suggest that pseudarthroses are attributable to vancomycin use.

\section{Level of Evidence: N/A; In Vitro Controlled Laboratory Study}

OTHER \& SPECIAL CATEGORIES

KEYWORDS: VANCOMYCIN, INFECTION, FUSION, ARTHRODESIS, PSEUDARTHROSIS

VOLUME 11 ISSUE 2 DOI: 10.14444/4012

PAGES 85 - 90

\section{Introduction}

Vancomycin is a bactericidal antibiotic that inhibits transglycosylation, weakening the cell wall and damaging the underlying cell membrane of gram-positive cocci. Topical "powdered" vancomycin has increased in popularity for elective, primary spine surgery with increasing supporting evidence each year. In one study of 1,512 patients, placing vancomycin directly into the wound decreased spine in- fections to $1.2 \%,{ }^{1}$ while another study of 911 patients showed a dramatic reduction in spine infections to $0.2 \%$, as compared to a historical control of $2.6 \%$ infection. ${ }^{2}$ A multicenter review of 2,311 patients reported a $2.4 \%$ infection rate in comparison to $5.1 \%$ in the study population without vancomycin. ${ }^{3}$ However, despite some promising retrospective reviews, a single randomized trial was unable to provide support for the use of vancomycin and a systematic review recommended caution. ${ }^{4}$ 
One of the criticisms and challenges of topical vancomycin use is the absence of a standard dose. The majority of published studies describe fixed quantities ( 1 or 2 grams of vancomycin) per patient, without adjustment for the size of the wound. When 1 gram of vancomycin is mixed into the bone graft and another 1 gram applied freely in a spine wound, the local concentration antibiotic ranges from 260-2900 $\mu \mathrm{g} / \mathrm{mL}$ in the immediate post-op period and 50-730 $\mu \mathrm{g} / \mathrm{mL}$ by the second post-operative day. ${ }^{2}$ The wide range is likely due to variability in wound size. Furthermore, the local concentration of vancomycin remains between 2 to 200 times higher than that recommended for the treatment of such severe infections as endocarditis and necrotizing fasciitis (15-20 $\mu \mathrm{g} / \mathrm{mL})^{5}$

With the variability in clinical outcomes and very high local concentration of vancomycin, we sought to better understand the consequences of topical vancomycin in an in vitro model. We hypothesized that high doses of vancomycin would have collateral damage and toxic effects to the proliferation and osteogenic capacity of mesenchymal stem cells (MSCs) in comparison to the control group. To test this hypothesis, we evaluated cell survival after a 24-hour exposure to vancomycin at a wide range of doses and assessed the MSCs capability for calcium deposition in an in vitro model.

\section{Materials and Methods}

Mesenchymal Stem Cell Harvest and Culture

Human MSCs (hMSCs) were isolated from the bone marrow obtained during preparation of the femoral canal obtained from elective total hip arthroplasties from 9 different male patients, who had a diagnosis of degenerative osteoarthritis or osteonecrosis (ages 55 to 75 years). The tissue was obtained adhering to local institutional guidelines, with the restriction that the data be analyzed and published in aggregate. The bone marrow was centrifuged at $500 \mathrm{~g}$ for 5 minutes. The supernatant was aspirated, and the remaining pellet was resuspended in $10 \%$ fetal bovine serum (FBS) media and plated using the plastic adhesion protocol on $75 \mathrm{~cm}^{2}$ flasks to select out hMSCs from the mixed population of cells in the marrow.
The hMSCs were cultured to confluence. Every three or four days, the media was aspirated, the flasks were washed with $1 \mathrm{x}$ Phosphate Buffered Saline (PBS), and fresh 10\% FBS media was added.

\section{Vancomycin Treatment}

Upon reaching confluence, the cells were trypsinized and replated at 3,200 cells/well on black, clear, flatbottom 96-well polystyrene plates. After two days, the cells were exposed to $100 \mu \mathrm{L}$ of vancomycin at 0 , $400,1600,3200,6400$ and $12800 \mu \mathrm{g} / \mathrm{mL}$ in insulintransferrin-selenium (ITS) media for 24 hours in a standard tissue culture carbon dioxide incubator at $37^{\circ} \mathrm{C}$, with a $\mathrm{CO}_{2}$ level of $5 \%$.

\section{Quantitative and Qualitative Assessment}

After 24 hours of exposure to vancomycin, the viability of the hMSCs was quantitatively assessed with a 15-minute incubation in PrestoBlue, a commercially available kit measuring the ability of the cells to maintain a reducing environment in their cytosol. After the reading, the liquid was aspirated and the cells were washed with $1 x$ PBS. Cell viability was then confirmed using a qualitative assessment with a 30-minute incubation in a Live-Dead Stain, a fluorescence-based assay using the dyes Calcein-AM and Ethidium Bromide to measure viable and dead cells, respectively.

\section{Statistical Methods}

A one-way ANOVA with Tukey-post test was used for comparison between vancomycin doses under a single culture condition. Our post-hoc power analysis indicated that we had sufficient statistical power to detect $20 \%$ or greater cell death.

\section{Osteogenic Differentiation}

To assess hMSC potential for bone formation, we used an in vitro osteogenic differentiation kit and Alizarin Red staining for calcium deposition. We expanded primary hMSCs isolated from bone marrow (as above) to confluence in normal 10\% FBS media on clear 6-well plates. The hMSCs were subjected to treatment with vancomycin at doses of $0,400,3200$, and $1200 \mu \mathrm{g} / \mathrm{mL}$ in ITS media for 24 hours, followed by a 2-hour "rescue" period in ITS and subsequent growth in osteogenic media for 22 days (per the StemPro Osteogenesis Differentiation ${ }^{\circledR}$ protocol). 
The negative control for this experiment consisted of non-treated hMSCs grown in ITS during the treatment period of the experimental group of cells and subsequently grown in MSC growth media for the duration of the experiment. Media was changed on the cells every 3-4 days.

After the appropriate 22 days of growth in osteogenic media (or growth media for the negative control), an Alizarin Red stain was performed on the plates. The media was aspirated, the wells rinsed with $1 \mathrm{x}$ PBS, and the cells fixed with $4 \%$ formaldehyde for $30 \mathrm{~min}$ utes. After rinsing the cells with distilled water, the cells were stained with $2 \%$ Alizarin Red S solution ( $\mathrm{pH}$ 4.2) for 2-3 minutes. The cells were again rinsed with distilled water, and images were taken.

\section{Results}

There was increased cell death with increased vancomycin dose. When aggregated across all nine patients, the data showed that hMSC death was $9.43 \%$ at $400 \mu \mathrm{g} / \mathrm{mL}(\mathrm{p}=0.047), 13.79 \%$ at $1600 \mu \mathrm{g} / \mathrm{mL}$ $(\mathrm{p}=0.0047), 19.35 \%$ at $3200 \mu \mathrm{g} / \mathrm{mL}(\mathrm{p}<0.0001)$, $24.82 \%$ at $6400 \mu \mathrm{g} / \mathrm{mL}(\mathrm{p}<0.0001)$ and $51.83 \%$ at $12800 \mu \mathrm{g} / \mathrm{mL}$ of vancomycin $(\mathrm{p}<0.0001)$ in comparison to the control group containing no vancomycin (Table 1). Qualitative Live-Dead staining also confirmed increased cell death with increased doses of vancomycin (Figure 1).

Minimal background staining with Alizarin Red was

Table 1. Mesenchymal stem cell death after 24 hour exposure to vancomycin.

\begin{tabular}{|l|r|r|}
\hline Vancomycin Concentration $(\boldsymbol{\mu g} / \mathbf{m L})$ & $\begin{array}{r}\text { \% Cell Death } \\
\text { compared to } \mathbf{\mu g} / \mathbf{m L}\end{array}$ & p-Value \\
\hline $\mathbf{0}$ & $($ control) & -- \\
\hline $\mathbf{4 0 0}$ & $9.43 \%$ & 0.047 \\
\hline $\mathbf{1 6 0 0}$ & $13.79 \%$ & 0.0047 \\
\hline $\mathbf{3 2 0 0}$ & $19.35 \%$ & $<0.0001$ \\
\hline $\mathbf{4 8 0 0}$ & $13.58 \%$ & 0.0043 \\
\hline $\mathbf{6 4 0 0}$ & $24.82 \%$ & $<0.0001$ \\
\hline $\mathbf{1 2 8 0 0}$ & $51.83 \%$ & $<0.0001$ \\
\hline
\end{tabular}

Statistically significant cell death was seen at all tested doses of vancomycin. Increased doses of of vancomycin were associated with increased cell death. seen when the hMSCs were grown for 21 days in routine culture media. When the hMSCs were instead grown under osteogenic conditions, there was clear evidence of calcium deposition by osteoblasts, confirming that exposure to vancomycin did not result in the loss of osteoblastic differentiation. Visually, only the highest dose of vancomycin tested had an effect on mineral deposition (Figure 2).

\section{Discussion}

Statistically significant cell death was seen at tested doses of vancomycin with higher doses of vancomycin resulting in higher death. At the concentrations typically seen in a wound in the immediate post-operative period, cell death ranged from $9.4 \%$ $(400 \mu \mathrm{g} / \mathrm{mL} ; \mathrm{p}=0.047)$ to $19.4 \%(3200 \mu \mathrm{g} / \mathrm{mL}$; $\mathrm{p}<0.0001)$. Increasing the dose further increased cell death, $24.8 \%$ at $6400 \mu \mathrm{g} / \mathrm{mL}(\mathrm{p}<0.0001)$ and $51.8 \%$ at $12800 \mu \mathrm{g} / \mathrm{mL}$ of vancomycin $(\mathrm{p}<0.0001)$. Qualitative assessments using live/dead stains and functional assays for mineral deposition confirmed that cell death and dysfunction was seen with high doses of vancomycin.

Despite the lack of significant high-quality evidence available in the literature, many surgeons have adopted the practice of using intrasite topical vancomycin. ${ }^{6}$ It's popularity is strongly associated with the consistent retrospective data supporting its use to decrease infection. ${ }^{7}$ Furthermore, the low cost of vancomycin and high cost associated with post-operative infection provides exceptional potential for cost savings. In high-risk patients undergoing spinal fusion, one study suggests that $\$ 438,165$ would be saved every 100 spinal fusion performed. ${ }^{8}$ Case reports of anaphylactoid reactions with circulatory collapse are rare. ${ }^{9}$ To our knowledge, the only other study evaluating pseudarthrosis after topical vancomycin is a rodent model relying on a known rhBMP-2 dose to provide $100 \%$ fusion. ${ }^{10}$ In humans, posterolateral fusion studies with $100 \%$ fusion rates required $20 \mathrm{mg}$ of rhBMP-2 per side. ${ }^{11}$

Vancomycin, however, may not be the "magic pixie dust" once thought to be. The benefits of vancomycin are not seen consistently ${ }^{12}$ and our study provides potential concern about MSC toxicity, 
which may be relevant in humans in the absence of rhBMP-2 or at doses of rhBMP-2 known to provide less than $100 \%$ fusion rates.

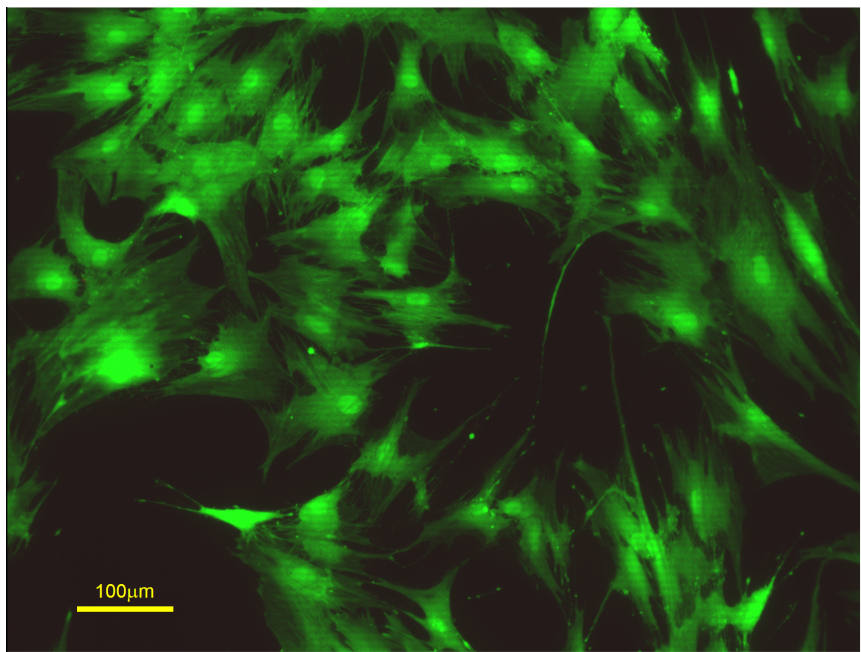

Vancomycin $(0 \mu \mathrm{g} / \mathrm{ml})$
It is known that locally delivered MSCs can increase bone formation in a scenario of otherwise inadequate amounts of autologous bone graft. ${ }^{13}$ Additionally, other studies with ceramic scaffolds have shown that

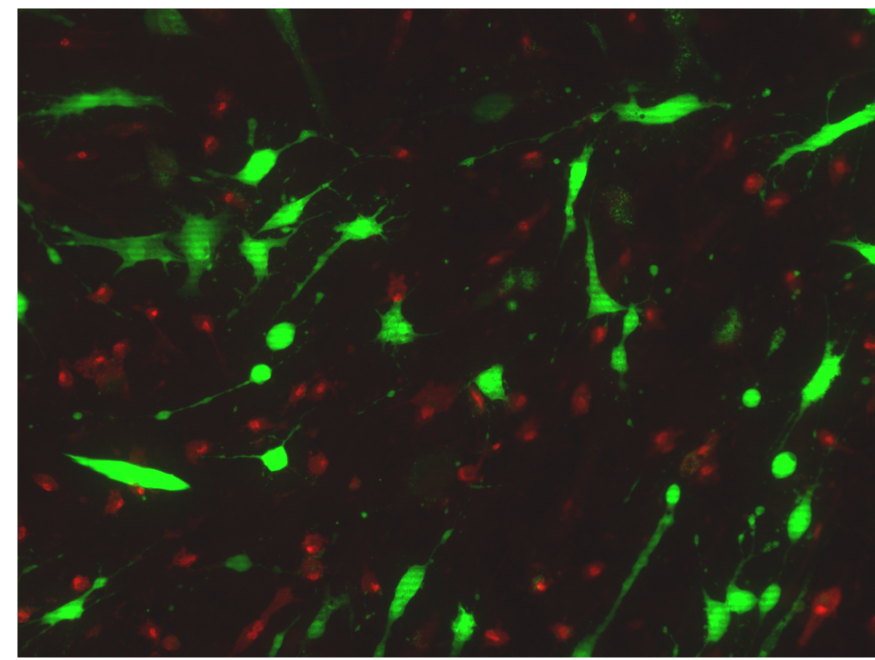

Vancomycin $(6400 \mu \mathrm{g} / \mathrm{ml})$

Fig. 1. Live/Dead Staining of human mesenchymal stem cells after vancomycin exposure. Increased death of human mesenchymal stem cells was observed after exposure to $6400 \mu \mathrm{g} / \mathrm{ml}$ of vancomycin as compared to control. Live cells are stained in green while dead cells are stained in red.

\section{Alizarin Red S}

\section{CALCIUM STAINING}

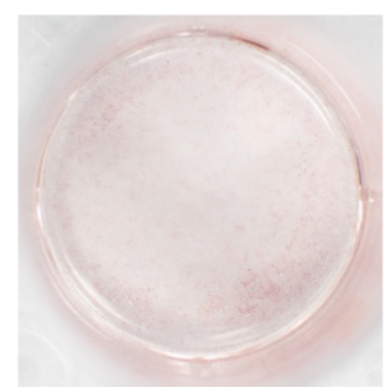

NEGATIVE CONTROL

Mesenchymal stem cells (MSCs) only
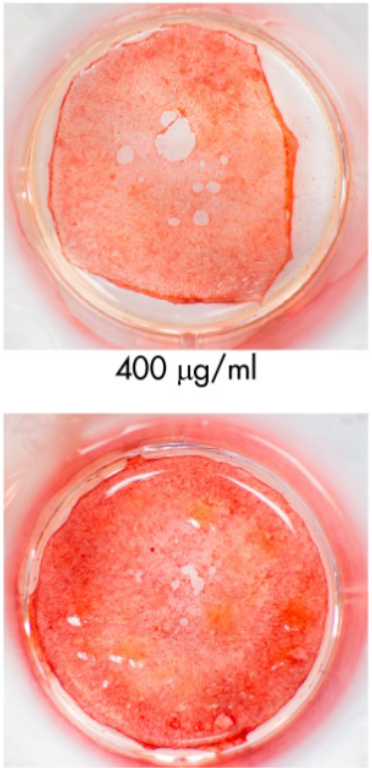

$4800 \mu \mathrm{g} / \mathrm{ml}$

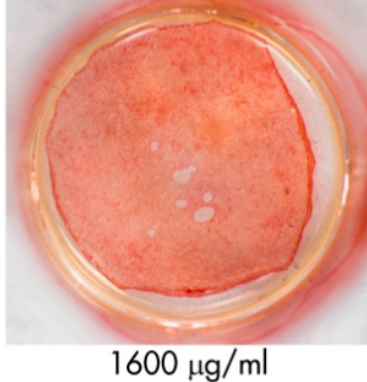

$1600 \mu \mathrm{g} / \mathrm{ml}$

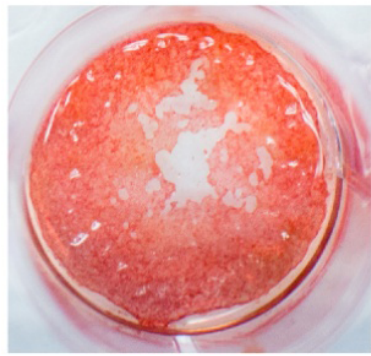

$6400 \mu \mathrm{g} / \mathrm{ml}$
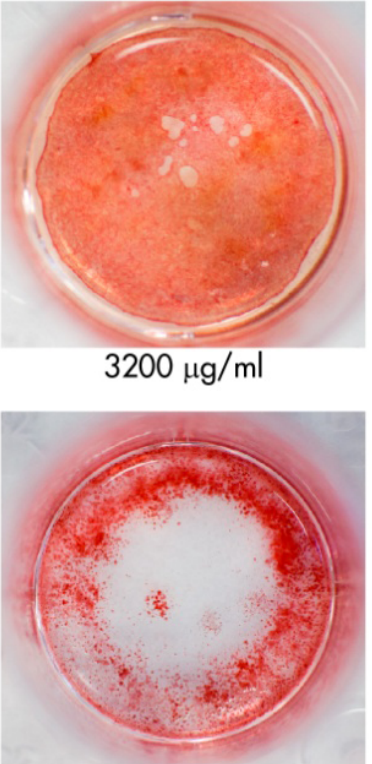

$12800 \mu \mathrm{g} / \mathrm{ml}$

\section{OSTEOBLASTS}

(DIFFERENTIATED FROM MSCs EXPOSED TO VANCOMYCIN)

Fig. 2. Functional assessment of human mesenchymal stem cells exposed to vancomycin. Alizarin Red staining was used to assess the function of MSCs that were previously exposed to 24 hours of vancomycin. Red staining indicates the presence of calcium deposition. While statistically significant cell death was seen at all tested doses, calcium deposition appeared to drop dramatically at the highest dose of vancomycin tested. 
low MSC concentration has much poorer rates of spinal fusion in comparison to a high MSC concentration group..$^{14}$ Therefore, one might speculate that a spinal fusion relying on a high ratio of a bone graft extender relative to autologous bone may be more sensitive to MSC death than a procedure where there is sufficient autograft for the fusion bed. Vancomycin induced toxicity is likely to be at greatest risk in procedures relying on extensive use of bone graft substitutes with poor volume of allograft.

The primary limitation of this study is that it is an in vitro study. Accordingly, this study does not establish a contraindication to the use of topical vancomycin nor establish a specific recommended dose. While all doses of vancomycin were toxic to hMSCs, it is unclear if the amount of early hMSC toxicity has a clinical consequence at the expected 6 months post-op period when bony fusion is expected. In the clinical setting, early hMSC cell death may very well be an appropriate price to pay for the bactericidal effect of vancomycin. The mineralization potential in vitro also may not directly correlate with bone forming potential in vivo under typical conditions in spinal fusion surgery.

Additionally, it is also important to note that this study does not provide any comment to the use of IV vancomycin in the peri-operative period (i.e. before incision and 24 hours post-op). The ideal antibiotic agent may differ from hospital to hospital depending on the local hospital antibiogram. Vancomycin is less efficient at killing gram-positive cocci than a traditional beta-lactam (in organisms sensitive to beta lactams) but has the benefit of being bactericidal against most gram-positive cocci except for enterococci and some tolerant staphylococci.

Nevertheless, given the consistently statistically significant hMSC death seen with increasing doses of vancomycin, surgeons should be cautious before using exuberant amounts of vancomycin.

\section{Conclusion}

The available literature suggests that topical vancomycin may be effective in reducing post-operative infections in spine surgery. While its use appears to be increasing in popularity, it is not the standard of care. Our in vitro study suggests that vancomycin has toxic effects on hMSCs, a cell population particularly important for bone formation.

In the absence of any clinical evidence suggesting that "more vancomycin is better," and our data suggesting that more vancomycin is harmful in vitro, surgeons electing to use topical vancomycin in spine surgery should restrict their use to the doses currently reported in the available published studies unless specific reasons exist otherwise. This study does not establish a contraindication to the use of vancomycin, nor does it suggest that pseudarthroses are attributable to vancomycin use.

\section{References}

1. Molinari RW, Khera OA, Molinari WJ, 3rd. Prophylactic intraoperative powdered vancomycin and postoperative deep spinal wound infection: 1,512 consecutive surgical cases over a 6-year period. European spine journal : official publication of the European Spine Society, the European Spinal Deformity Society, and the European Section of the Cervical Spine Research Society. 2012 Jun;21 Suppl 4:S476-82.

2. Smith JS, Shaffrey CI, Sansur CA, Berven SH, Fu KM, Broadstone PA, et al. Rates of infection after spine surgery based on 108,419 procedures: a report from the Scoliosis Research Society Morbidity and Mortality Committee. Spine. 2011 Apr 1;36(7):556-63.

3. Devin CJ, Vaccaro AR, McGirt MJ, Chotai S, Youssef JA, Orndorff D, et al. 166 Does the Use of Intrawound Vancomycin Decrease the Risk of Surgical Site Infection After Elective Spine Surgery?-A Multicenter Analysis. Neurosurgery. 2015 Aug;62 Suppl 1:220.

4. Evaniew N, Khan M, Drew B, Peterson D, Bhandari $M$, Ghert $M$. Intrawound vancomycin to prevent infections after spine surgery: a systematic review and meta-analysis. European spine journal : official publication of the European Spine Society, the European Spinal Deformity Society, and the European Section of the Cervical Spine Research Society. 2015 Mar;24(3):533-42. 
5. Liu C, Bayer A, Cosgrove SE, Daum RS, Fridkin SK, Gorwitz RJ, et al. Clinical practice guidelines by the infectious diseases society of america for the treatment of methicillin-resistant Staphylococcus aureus infections in adults and children: executive summary. Clin Infect Dis. 2011 Feb 1;52(3):285-92.

6. Kang DG, Holekamp TF, Wagner SC, Lehman RA, Jr. Intrasite vancomycin powder for the prevention of surgical site infection in spine surgery: a systematic literature review. Spine J. 2015 Apr 1;15(4):762-70.

7. Xiong L, Pan Q, Jin G, Xu Y, Hirche C. Topical intrawound application of vancomycin powder in addition to intravenous administration of antibiotics: A meta-analysis on the deep infection after spinal surgeries. Orthop Traumatol Surg Res. 2014

Nov;100(7):785-9.

8. Godil SS, Parker SL, O'Neill KR, Devin CJ, McGirt MJ. Comparative effectiveness and cost-benefit analysis of local application of vancomycin powder in posterior spinal fusion for spine trauma: clinical article. J Neurosurg Spine. 2013 Sep;19(3):331-5.

9. Mariappan R, Manninen P, Massicotte EM, Bhatia A. Circulatory collapse after topical application of vancomycin powder during spine surgery. J Neurosurg Spine. 2013 Sep;19(3):381-3.

10. Mendoza MC, Sonn KA, Kannan AS, Bellary SS, Mitchell SM, Singh G, et al. The effect of vancomycin powder on bone healing in a rat spinal rhBMP-2 model. J Neurosurg Spine. 2016 Apr 1:1-7. 11. Boden SD, Kang J, Sandhu H, Heller JG. Use of recombinant human bone morphogenetic protein-2 to achieve posterolateral lumbar spine fusion in humans: a prospective, randomized clinical pilot trial: 2002 Volvo Award in clinical studies. Spine. 2002
Dec 1;27(23):2662-73.

12. Martin JR, Adogwa O, Brown CR, Bagley CA, Richardson WJ, Lad SP, et al. Experience with intrawound vancomycin powder for spinal deformity surgery. Spine. 2014 Jan 15;39(2):177-84.

13. Curylo LJ, Johnstone B, Petersilge CA, Janicki JA, Yoo JU. Augmentation of spinal arthrodesis with autologous bone marrow in a rabbit posterolateral spine fusion model. Spine. 1999 Mar 1;24(5):434-8; discussion 8-9.

14. Minamide A, Yoshida M, Kawakami M, Yamasaki S, Kojima H, Hashizume H, et al. The Use of Cultured Bone Marrow Cells in Type I Collagen Gel and Porous Hydroxyapatite for Posterolateral Lumbar Spine Fusion. Spine. 2005;30(10):1134-8.

\section{Disclosures \& COI}

All authors report no relevant disclosures or conflicts of interest.

\section{Corresponding Author}

Alan B.C. Dang, MD, University of California, San Francisco, Department of Orthopaedic Surgery, 500 Parnassus Ave., MU-320W, 3rd Floor, San Francisco, CA 94143. alan.dang@ucsf.edu.

Published 4 April 2017.

This manuscript is generously published free of charge by ISASS, the International Society for the Advancement of Spine Surgery. Copyright @ 2017 ISASS. To see more or order reprints or permissions, see http://ijssurgery.com. 